\title{
Olgu Sunumları Eşliğinde Palmar Fibromatozis Değerlendirimi ve Tedavisi
}

\author{
The Assessment and Treatment of Palmar Fibromatosis with Case Presentations
}

Şule Şahin Onat, Sibel Ünsal Delialioğlu

Ankara Fizik Tedavi Eğitim ve Araştırma Hastanesi, Ankara, Türkiye

\section{Özet}

Palmar fibromatozis distal palmar çizginin her iki yanında, parmak tabanında olabilen sert nodüldür. Geriatri polikliniklerinde sık karşılaştığımız fakat ağrısız olduğu için gözden kaçabilen, uygun tedavi seçimiyle hastanın fonksiyonel kısıtılıklarında belirgin düzelme sağlanan bir hastalıktır. Birinci olgu seksen iki yaşında erkek hasta bir yıldır sağ el 4.parmakta, ikinci olgu altmış sekiz yaşında erkek hasta on beş yıldır sol el 3.parmakta, üçüncü olgu seksen beş yaşında bayan hasta otuz yıldır sol elinde 4.ve 5. parmaktaki hareket kısıtlılıklarıyla başvurdu. Parmak gonyometrisiyle ölçülen eklem hareket açıklığı birinci olguda 4. metakarpofalangeal (MKF) eklemde 0-80 derecede, ikinci olguda sol 3. MKF eklemde 0-60 derecede, üçüncü olguda sol 4. MKF eklemde 0-40 derecede, PIF eklemde 0-80 derecede; sol 5. MKF eklem 0-40 derecede, PIF eklemi 0-90 derecedeydi. Olgulara idiopatik palmar fibromatozis tanısı konularak fizik tedavi programı verildi. Magnetik rezonans görüntülemelerinde hem T1 hem de T2 ağırlıklı kesitlerde hipointens lezyon gözlenmesi üzerine cerrahi tedaviye gönderildi. Bu sunudaki amacımızda olgularımızda olduğu gibi fiziyatrist olarak PF tanısını ve tedavisini gözden geçirmektir. (Türk Osteoporoz Dergisi 2013;19: 52-5)

Anahtar kelimeler: Palmar fibromatozis, tedavi, cerrahi tedavi kararı

\section{Summary}

Palmar fibromatosis is a hard nodule on the base of the finger that runs through both sides of distal palmar line. We come across this condition quite often in our geriatrics clinic, yet it is usually overlooked because it does not cause any pain, even though with proper care and treatment patient's functional limits can increase significantly. In the study, 3 patients came to our clinic with limited mobility complaint on their fingers. First case, an 82-year old male patient, had this complaint on his right hand's 4th finger for over a year. Second case was a 68-year old male patient with the same complaint on his left hand's 3rd finger for 15 years and finally, third case was an 85-year old female patient with complaint on her left hand's 4th and 5th fingers for 30 years. Finger goniometry results for joint movement range were 0-80 degrees in 4th metacarpophalangeal (MCP) joint in the first case, 0-60 degrees in left 3rd MCP joint in second case and 0-40 degrees in left 4th MCP joint, 0-80 degrees in proximal interphalangeal joint, 0-40 degrees in 5th MCP joint and 0-90 in proximal interphalangeal joint on third case. All patients were diagnosed with idiopathic palmar fibromatosis and given physical therapy programs. The cases with hypointense lesions, seen on both T1 and T2 weighted MRI slices, were referred to surgery. Our main purpose in this presentation is to review PF diagnosis and treatment as physiatrists. (Turkish Journal of Osteoporosis 2013;19: 52-5)

Key words: Palmar fibromatosis, treatment, surgical treatment decision

\section{Giriş}

Palmar fibromatozisin (Dupuytren hastalığı) genel populasyondaki prevalansı \%1-2'dir (1,2). Yaşlanmayla bu oran daha da artmaktadır. Geriatri polikliniklerinde sık karşılaştığımız fakat ağrısız olduğu için hasta dile getirmedikçe gözden kaçan, uygun tedavi seçimiyle hastanın fonksiyonel kısıtlılıklarında belirgin düzelme sağlanan bir hastalıktır. Bu sunudaki amacımızda fiziyatrist olarak palmar fibromatozis tanısını, tedavisini ve cerrahi tedaviye karar vermedeki değerlendirimi tartışmaktır.

\section{Olgu}

1. Olgu: Seksen iki yaşında erkek hastada bir yıldır olan sağ el 4.parmakta hareket kısıtlıı̆ı mevcuttu. Parmak gonyometrisiyle ölçülen eklem hareket açıkığı 4. metakarpofalangeal (MKF) eklemde 0-80 derecedeydi. Proksimal interfalangeal (PIF) ve distal interfalangeal (DIF) eklemlerin hareket açıklıkları normaldi (Resim 1).

2. Olgu: Altmış sekiz yaşında erkek hastanın on beş yıldır olan sol el 3.parmakta hareket kısıtılığı mevcuttu. Parmak 
gonyometrisiyle ölçülen eklem hareket açıklığı sol 3. MKF eklemde 0-60 derecedeydi. Proksimal interfalangeal ve DIF eklemlerin hareket açıklıkları normaldi (Resim 2).

3.Olgu: Seksen beş yaşında bayan hastada otuz yıldır olan sol elinde 4.ve 5. parmakta hareket kısıtlılıkları mevcuttu. Parmak

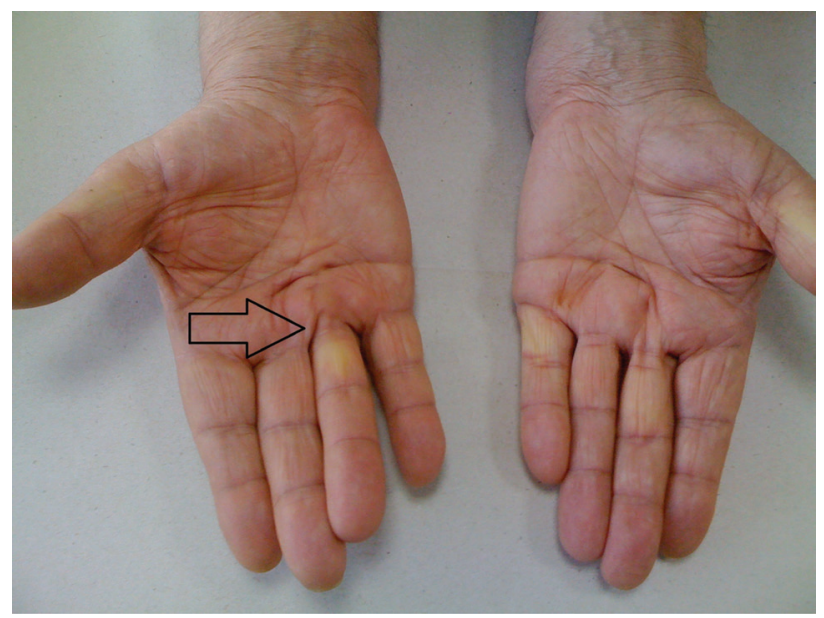

Resim 1. Birinci olgunun sağ el 4.parmak MKF eklemindeki kontraktürün görüntüsü

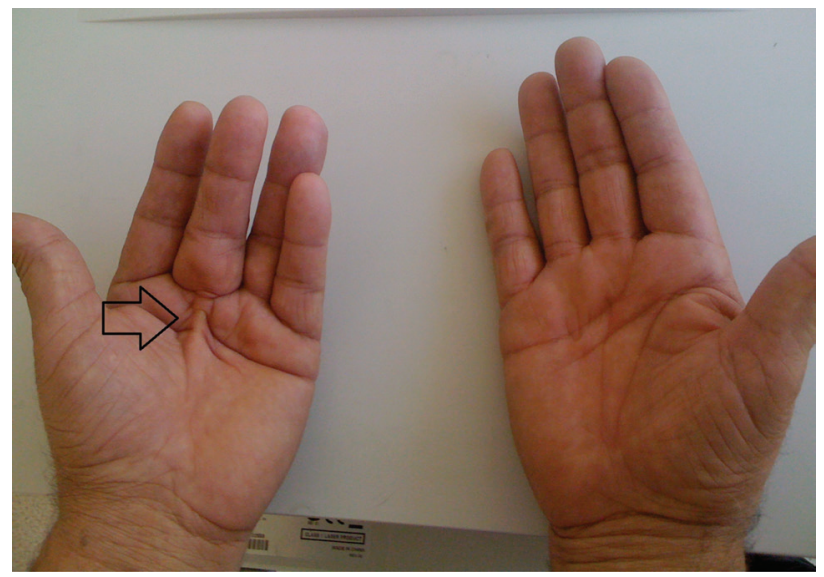

Resim 2. ikinci olgunun sol el 3.parmak MKF eklemindeki kontraktürün görüntüsü

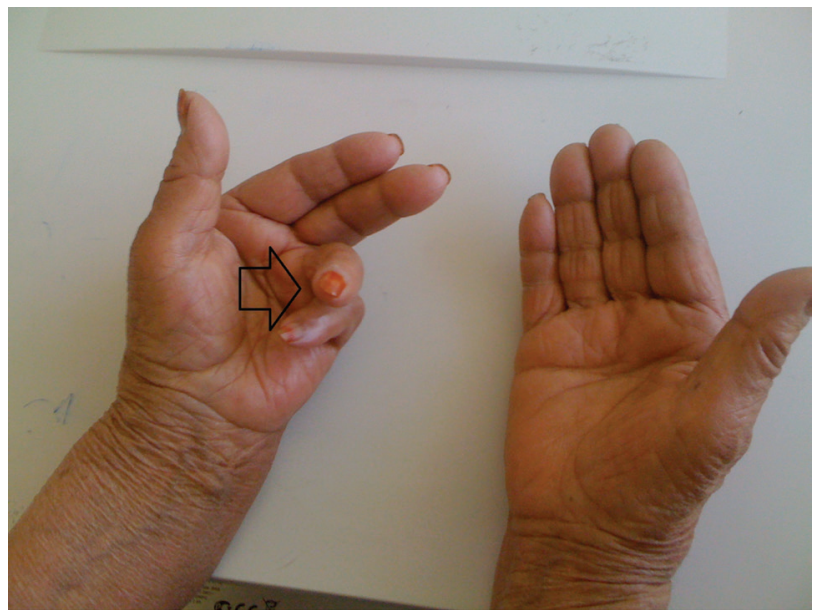

Resim 3. Üçüncü olgunun sol elinde 4.ve 5. parmakta MKF eklemindeki kontraktürün görüntüsü gonyometrisiyle ölçülen eklem hareket açıklığı sol 4. MKF eklemde 0-40 derecede, PIF eklemde 0-80 derecede; sol 5. MKF eklem 0-40 derecede, PIF eklemi 0-90 derecedeydi. (Resim 3).

Her üç hastanın özgeçmişinde travma, herhangi bir sistemle ilgili hastalık veya kronik ilaç kullanım öyküsü ve soygeçmişinde özellik yoktu. Sistemik muayeneleri normaldi. Laboratuvar incelemeleri normaldi. Hastaların magnetik rezonans görüntülemelerinde (MRG) hem T1 hem de T2 ağılıklı kesitlerde düşük sinyal yoğunluklu hipointens lezyon gözlendi (Resim 4,5). Tedavide dorsal atel uygulamasıyla birlikte ele 20 dakika parafin, 6 dakika 3 watt $\backslash \mathrm{cm}^{2}$ su içi ultrason, 20 tekrarlı eklem hareket açıklığı ve germe egzersizlerini içeren 15 seanslık fizik tedavi programı verildi. Tedavi sonrası birinci olguda eklem hareket açıklığı 4. MKF eklemde 0-70 derecede, ikinci olguda 3. MKF eklemde 0-50 derecede, üçüncü olgu olguda sol 4. MKF eklemde 0-40 derecede, PIF eklemde 0-70 derecede; sol 5. parmakta MKF eklem 0-30 derecede, PIF eklemi 0-70 derecedeydi. Olguların eklem hareket açıklı̆ında düzelme olmamasıyla birlikte MRG'lerinde hipointens lezyon gözlenmesi nedeniyle cerrahi tedaviye karar verildi. Operasyon sonrası birinci ve ikinci hastada eklem hareket açıklığı tam kazanıldı, üçüncü hastaya ulaşılamadığı için sonuçlar hakkında bilgi edinilemedi.

\section{Tartışma}

Palmar fibromatozisin 65 yaş üstünde prevalansı \%24'ün üzerindedir. Tablo \%42-60 vakada bilateral seyretmektedir (2). $\mathrm{Bu}$ lezyonlar erkeklerde daha yaygındır ve erkek:kadın oranı Avrupa'da 7:1, Amerika'da 1.7:1 olarak bildirilmiştir $(3,4)$. Ciddi seyirli hastalarda 30-40 yaşlarında başlamakta, sıklıkla çift taraflı olarak, elin radyal tarafını etkilemekte ve birden fazla parmak tutulumu olmaktadır (5). Epilepsi, alkolizm, diabetes mellitus, kronik akciğer hastalığı, HIV ve kompleks bölgesel ağrı sendromuyla ilişkili olduğu bilinmektedir (5).

Elin distalindeki bir buruşukluk olan palmar fibromatozis, adından da anlaşıldığı gibi klinikte elin palmar yüzeyinde subkutan nodül olarak prezente olmaktadır. Bu nodüller fibroz kord veya bandlarla yavaş olarak ilerlemekte, bitişik fleksör tendonlarda çekilmeye neden olmakta ve parmaklarda fleksör kontraktürle sonuçlanmaktadır. Hastalık MKF kontraktürü 30 derecenin üstünde olduğunda belirgin olmakta ve hasta elini masa gibi düz bir zeminin üstüne koyduğunda elin palmar yüzünün yere temas etmememesiyle 'tabletop testi' pozitif olarak kabul edilmektedir (3). En sık 4. ve 5. zonu, daha sonra da 2. ve 3. zonu etkilemektedir (2). Woodruff ve Waldren sınıflandırmasına göre hastalık 5 evrede değerlendirilmektedir (6): Lıre ı: MKF eklemde hiperekstansiyon olmakla beraber el düz olarak yere değmektedir. Evre 2:Tek bir bantta gerginlik vardır, sadece MKF eklemde kontraktür görülmektedir. Evre 3: Tek bantta gerginlik vardır, hem MKF eklem hem de PIF eklemde kontraktür bulunmaktadır. Evre 4: Klinik 3. evredeki gibidir ama iki parmakta kontraktür vardır. Evre 5: Parmak avuç içine bükülmüştür, amputasyon gerekmektedir. Histopatolojik olarak hem düz kas hücresi hem de fibroblast özelliği taşıyan aktif miyofibroblastlar 
ve yoğun kollajen dokudan oluşmaktadır (7). Woodruff ve Waldren sınıflandırmasına göre olgularımızın ilki ve 2.'si evre 2, 3.'sü ise evre 4 olarak kabul edildi.

Tedavi lezyonun ilerleme hızına ve tutulumun ciddiyetine göre planlanmaktadır. Cerrahi olmayan tedavi kontraktürü olmayan, izole nodülü olan hastalarda tercih edilebilir (8). Nodülü kordun içine büyüyüp kontraktüre yol açan çoğu hastada fonksiyonlar kısıtlanmakta ve agresif tedavi gerekmektedir (8). Bundan dolayı fizik tedavi tek başına genelde etkin değildir ve cerrahi sonrası dönemde çok daha faydalı olduğu bildirilmiştir (8). Olgularımızda da uygulanan fizik tedavi programının etkinliği

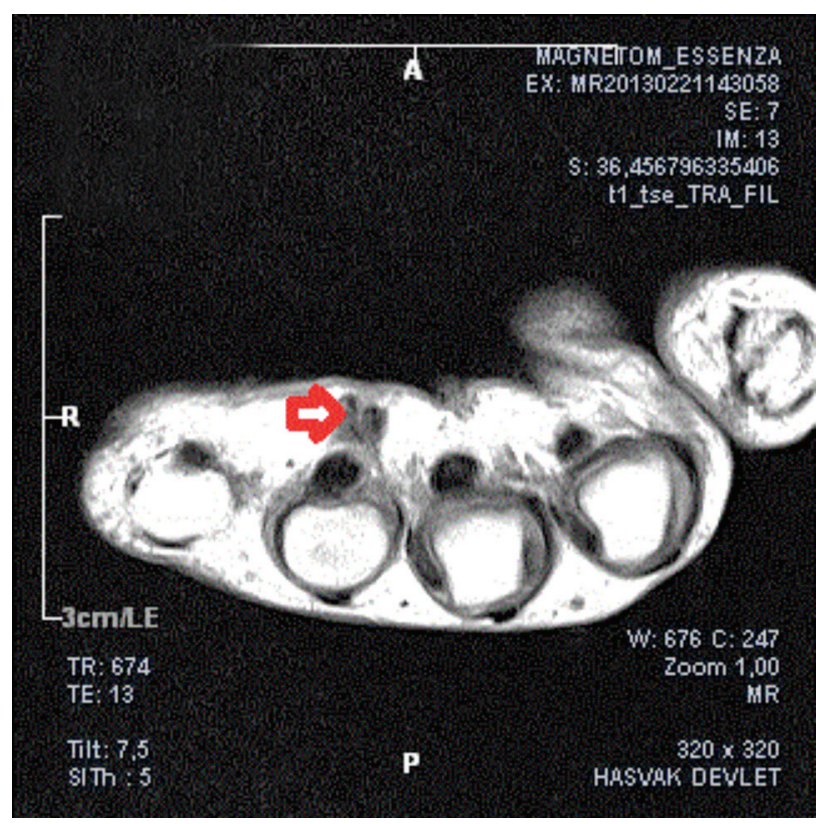

Resim 4. Birinci olgunun MRG'de T1 ağırlıklı kesitteki hipointens lezyon görüntüsü

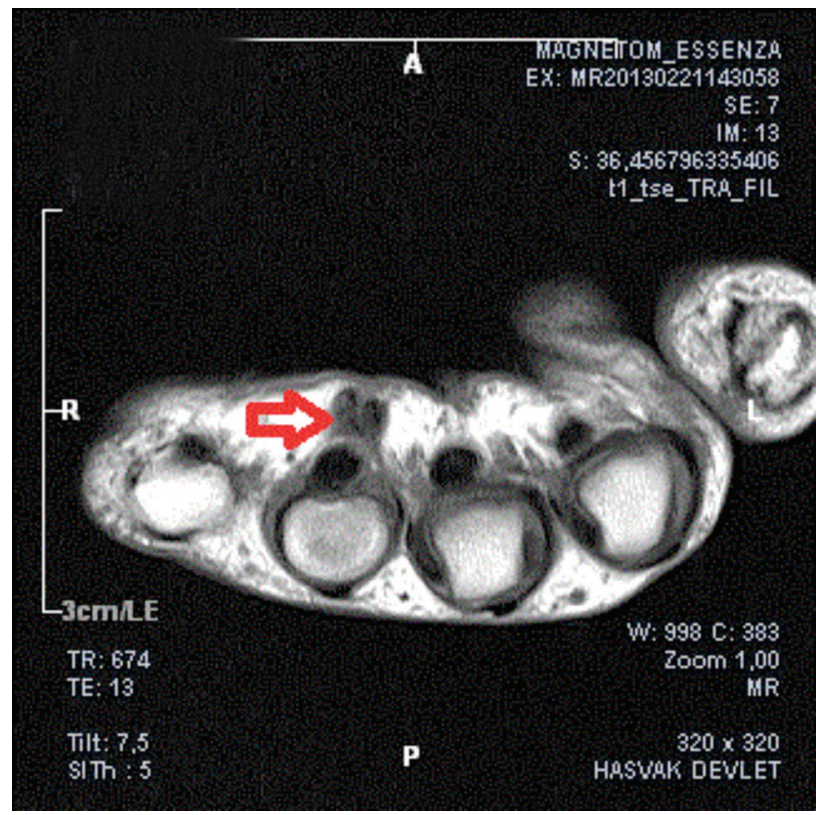

Resim 5. Birinci olgunun MRG'de T2 ağırlıklı kesitteki hipointens lezyon görüntüsü için başarı oranları beklenmese de hastaların cerrahi tedaviyi ısrarla reddetmelerinden dolayı programları düzenlemiş, nitekim literatürle uyumlu olarak eklem hareket açıklıklarında kazanç sağlanamamıştı. Cerrahi olmayan tedavilerde ultrasonu içeren ısıtıcı fizik tedavi modaliteleri, eklem hareket açıklı̆ı ve germe egzersizleri, atelleme uygulanabilmektedir (3). El bileğinin hafif fleksiyonda, parmakların tam ekstansiyonda olduğu dorsal atel kullanımı önerilmektedir. Operasyondan sonraki dönemde de rekurens oranını azaltmak için ilk 3 hafta egzersiz ve temizlik dışında atel kullanımı sürekli olmalıdır (5). Atelin gece kullanımına ise en az 3 ay süreyle devam edilmelidir (5). 5-florourasil enjeksiyonu ve hiperbarik oksijen tedavisinin son yıllardaki popularitesi artmaktadır (9) Yine pnömatik ekstansiyon uygulamalarının da başarısından sıkça sözedilmektedir. Özellikle operasyona aday olan hastalarda, operasyondan önce 3 hafta süreyle pnömatik ekstansiyon uygulanmasıyla kontraktürde 5-60 derecelik azalmalar olduğu bildirilmiştir (10).

Palmar fibromatozis tedavisindeki cerrahi endikasyon MKF ve PIF eklemdeki 30 derece ve üzerindeki fleksiyon kontraktürüdür (3). MKF eklemdeki kontraktürde asıl sorumlu yapı palmar aponevrozun pretendinöz bandıdır ve bunun gevşetilmesi kolay olmaktadır. PIF eklemdeki kontraktürde sadece fasya değil santral ve lateral kordlar da olaya eklendiği için düzeltmek daha zordur. Operasyon için PIF eklemdeki kontraktürün 30 dereceye ulaşması beklenmelidir. Çünkü bu derecenin altındaki kontraktürde ameliyatın kendisi de kontraktüre yol açabilmektedir. DIF eklemde fleksiyon kontraktürü daha nadirdir ve tedavi başarısı da daha düşüktür. Operasyonda fasyotomi, bölgesel ve yaygın fasyektomi ve dermofasyektomi yapılmaktadır.

Palmar fibromatozisin erken proliferatif dönemdeki cerrahisinden sonra beklenen rekurens oranı \%30-40 civarındadır. Çünkü lezyon proliferatif fazda yüksek hücreselliğe sahiptir. Lezyon olgunlaştıkça hücreselliği azalmakta ve kollajen içeriği artmaktadır. Yüksek kollajen içerikli lezyonun cerrahi sonrası rekurens prevalansı daha düşüktür (11). Bundan dolayı palmar fibromatozis tanısı klinik olarak konulmakta ama cerrahi tedavi planlanıyorsa. magnetik rezonans görüntüleme kullanılmaktadır. Yacoe ve ark.ları da cerrahi tedaviye karar vermede magnetik rezonans görüntülerin önemini vurgulamışladır (12). Çünkü lezyonunun hücreselliği ve kollajen oranı magnetik rezonans görüntüleriyle uyumlu olmaktadır. T1 ve T2 ağırlıklı MRG'de gözlenen düşük sinyal yoğunluğu lezyonun hiposelüler ve kollajenden zengin olduğunu göstermektedir (12). T2 ağırlıklı MRG'de gözlenen orta sinyal yoğunluğu lezyonun daha selüler olduğunu, dolayısıyla lokal rekurensin daha sık beklendiğini göstermektedir. Lezyon T2 ağırlıkı MRG'de orta veya yüksek yoğunlukta sinyal veriyorsa, lokal rekurens oranını azaltmak için lezyon matüre olana kadar yani daha hiposelüler olana kadar cerrahi geciktirilmelidir (12). Bizim olgularımızda T1 ve T2 ağırlıklı MRG'de düşük yoğunluklu sinyaller olması, nodüllerin hiposelüler ve kollajenden zengin olduğunu göstermektedir. Zaten hastalarımızın fizik tedavi programından fayda görmemesi ve fonksiyonelliklerinin etkilenmesinin sonucunda magnetik rezonans görüntülerinin de cerrahi tedaviyi desteklemesiyle cerrahi tedavi kararı alınmıştır. 
Sonuç olarak sık karşılaştığımız fakat ağısıı olduğu için gözden kaçabilen palmar fibromatozise, uygun tedaviyle hastanın fonksiyonel kısıtlılıklarında belirgin düzelme sağlandığı için gereken önem verilmelidir.

\section{Kaynaklar}

1. Enzinger FM, Weiss SW. Soft tissue tumors. St Louis: Mo: Mosby; 1995.

2. Laskin WB, Weiss SW. Benign fibrous lesions. In: Bogumill GP, editors.Tumors of the hand and upper limb. Edinburgh, Scotland: Churchill Livingstone; 1993. p. 224-43.

3. Black EM, Blazar PE. Dupuytren disease: an evolving understanding of an age-old disease. J Am Acad Orthop Surg 2011;19:746-57.

4. Anthony SG, Lozano-Calderon SA, Simmons BP, Jupiter JB. Gender ratio of Dupuytren's disease in the modern U.S. population. Hand (N Y) 2008;3:87-90.

5. Kuran B. El ve El Bileği Ağrısı Nedenleri ve Muayenesi. In: Beyazova M, Kutsal YG, editors. Fiziksel Tıp ve Rehabilitasyon Kitabı. Cilt 2. Güneş Tıp Kitabevi. Ankara; 2011.p 2035-52.
6. Woodruff MJ, Waldram MA. A clinical grading system for Dupuytren's contracture. J Hand Surg 1998;23:303-5.

7. Verjee LS, Midwood K, Davidson D, Essex D, Sandison A, Nanchahal J. Myofibroblast distribution in Dupuytren's cords: Correlation with digital contracture. J Hand Surg Am 2009;34:1785-94.

8. Reilly RM, Stern PJ, Goldfarb CA. A retrospective review of the management of Dupuytren's nodules. I Hand Surg Am 2005:30:1014-8.

9. Bansal V, Naidu SH. Dupuytren's disease. Current Opinion in Orthopedics 2005; 16:236-9.

10. Beyermann K, Jacobs C, Prommersberger KJ, Lanz U. Preoperative Intermittent Pneumatic Soft-Tissue Distraction in Patients with severe Dupuytren's Contracture. Handchir Mikrochir Plast Chir 2002;34:118-22.

11. Balaguer T, David S, Ihrai T, Cardot N,Daideri G, Lebreton E. Histological staging and Dupuytren's disease recurrence or extension after surgical treatment: A retrospective study of 124 patients. J Hand Surg Eur 2009;34:493-6.

12. Yacoe ME, Bergman AG, Ladd AL, Hellman BH. Dupuytren's contracture: MR imaging findings and correlation between MR signal intensity and cellularity of lesions. AJR Am J Roentgenol 1993;160:813-17 